\title{
Assessment of HIV/AIDS Stigma in a Rural Namibian Community
}

\author{
Penehafo Angula, Busisiwe Purity Ncama, Janet Frohlich \\ University of Namibia, Windhoek, Namibia \\ Email: pangula@unam.na
}

Received 2 June 2015; accepted 4 September 2015; published 7 September 2015

Copyright (C) 2015 by authors and Scientific Research Publishing Inc.

This work is licensed under the Creative Commons Attribution International License (CC BY). http://creativecommons.org/licenses/by/4.0/

(c) (i) Open Access

\section{Abstract}

Namibia has been affected by the Human Immunodeficiency Virus (HIV) and Acquired Immune Deficiency Syndrome (AIDS) pandemic with infected and affected persons experiencing stigma at different levels. Despite the high level of knowledge on HIV/AIDS, stigma remains a challenge. It was for this reason that this paper describes and measures the level of HIV/AIDS stigma in a rural community in Namibia. Mixed methods were used to collect data from 224 participants consisting of 93 people living with HIV/AIDS (PLWHA) who were recruited voluntarily from their support groups, 77 family members nominated by PLWHA participants, 31 community members who were recruited through simple random sampling and 19 opinion leaders who were purposefully selected and four health care workers from an Antiretroviral clinic who were available at the time of this study. Three measurement instruments namely HIV/AIDS Stigma Instrument-PLWHA (HASIP), Family \& Community Stigma Instrument (F\&C-SI) and HIV/AIDS Stigma Instrument-Nurse (HASIN) were used. In-depth interviews were conducted to complement the quantitative results. The study found that stigma manifests in different ways and results revealed that verbal abuse $(55 \%, n=$ 50, PLWHA), social isolation $(73 \%, n=67)$, negative self-perception $(33 \%, n=30)$, and household stigma ( $26 \% n=19$, family members) were the most common form of stigma experienced by PLWHA. Furthermore health care workers reported stigma of association $(50 \%, n=2)$ as care providers for people living with HIV/AIDS. The study concluded that stigma exists although some scores such as fear of contagion and workplace stigma were low. Therefore, interventions in knowledge on basic facts of HIV transmission need to be strengthened. Nonetheless the majority of participants confirmed their willingness to care for sick relatives with HIV and AIDS. This study did not explore stigma of association against caregivers with other participants other than the four health care workers from the antiretroviral clinic. Future researchers can take this further.

\section{Keywords}

People Living with HIV/AIDS (PLWHA), Family \& Community Stigma Instrument, Ongenga Constituency, Namibia 


\section{Introduction}

Human Immunodeficiency Virus (HIV) and Acquired Immune Deficiency Syndrome (AIDS) have affected Namibia in the same way that they have impacted on many other southern African countries. As a largely semidesert coastal country with a population of 2.3 million and an HIV prevalence rate of $18.8 \%$ in 2010 [1] Namibia, not only needs to understand its local epidemic, but to address the public health issues associated with it, such as stigma and discrimination.

Namibia, with its small population of 2.3 million and limited resources has been severely affected by the HIV/ AIDS pandemic, with the first case been diagnosed in 1986. In 2008, the number of PLWHA in Namibia was recorded as 230,000, while deaths related to HIV/AIDS were recorded as 17,000 and orphans ( 0 - 17 years of age) due to HIV/AIDS were recorded as 70,000 [2]. According to a 2010 Ministry of Health report 5800 new infections were registered in 2008-2009, which amounts to 16 HIV infections per day. It was further documented that stigma and discrimination are some of the contributing factors that have a link to the epidemic, although this was not substantiated by research [3].

Stigma as conceptualized by Goffman (1963) (who created the framework for its study), was defined as an "undesirable or discrediting attribute" that an individual possesses, thereby reducing his status in the eyes of the society [4]. HIV/AIDS was the latest stigmatized health condition at the time of the study (2009-2011), having followed Leprosy, Sexual Transmitted Diseases (STD), Tuberculosis (TB), Epilepsy and mental illness [5].

Stigma is the major obstacle in HIV prevention, as it prevents people from disclosing their status due to a fear of rejection and discrimination. It blocks the treatment adherence as PLWHA will avoid being seen going to the ARV clinics to collect their medication regularly, prevent men to accompany their partners and wives to prevention of mother-to-child transmission (PMTCT) services as they are afraid to be tested for HIV and being stigmatized if they are positive [6]. Above all, stigma prevents PLWHA from living positively, and the accompanying aversion to being tested and seeking treatment fuels the epidemic [6].

According to several authors, PLWHA in Namibia have not been immune to stigma, which manifests in different ways [7]-[10]. A study by Angula reported that stigma includes being rejected by community, thrown out of their homes by families and relatives and denied employment [6].

Keulder, in his study in the four regions (rural and urban) of Namibia with PLWHA who were HIV support group members revealed that although HIV/AIDS stigma is still a problem, it is declining compared to ten years ago [7]. Additionally, a recent study that was conducted by Nghifikwain 2011 with ten PLWHA at the ARV clinic of Oshakati Intermediate Hospital, in northern rural Namibia, revealed that people still experiencing stigma in their families and communities although they reported low stigma in health facilities [9].

Many PLWHA in Namibia are being sent to rural areas when they become sick, and researchers have found that stigma is higher in rural than urban areas due to lack of correct information on HIV transmission. There is therefore a need for community-wide programs in rural communities to reduce stigma associated with HIV/ AIDS [11].

Several studies that were conducted on stigma in Namibia are qualitative and exploratory in nature, and none of those studies have quantified stigma levels and its extent. Quantifying the level of stigma will assist in planning HIV/AIDS stigma reduction interventions and development of anti-stigma strategies. The aim of this study was therefore to determine the level and extent of stigma in a rural northern Namibian community and provide a baseline for future stigma studies in the Namibian context on which targeted intervention could be based.

\section{Methods}

\subsection{Study Design}

This study was a mixed methods design using both quantitative and qualitative approaches. The concurrent embedded strategy which was used in this study provided a comprehensive understanding of stigma and the resulting discrimination and enables the development of appropriate intervention strategies. According to Cresswell in his mixed methods approach combating stigma requires rich and informative data to contribute to new knowledge and assist in finding suitable solutions [12]. It was for these reasons that quantitative method was used to quantify the level of stigma and discrimination. While qualitative method was used to help in understanding HIV/AIDS stigma phenomenon to get an insight into its causes, impacts and how to reduce it. 


\subsection{Study Setting and Participants}

The study used a multi-sampling approach for which four groups of participants from a rural community in Ongenga constituency were recruited namely: people living with HIV/AIDS (PLWHA) who are Opawa Support Group members, their families or friends, community members and opinion leaders, and finally health care workers from antiretroviral (ARV) clinic. The majority of the participants were women $(n=164)$ and their age ranges from 18 - 81 years old. They were recruited as follows:

Group 1: PLWHA who are Opawa Support Group members were selected purposively by their coordinators due to their HIV status being known by their coordinators. Ninety three eligible PLWHA who were willing to participate were recruited. They were requested to nominate a family member or a friend of their choice to whom they have disclosed their HIV status to be Group 2 study participants. That was done to ensure confidentiality about their HIV positive status. Some PLWHA opted not to nominate any family member or friend however no reasons were given for their decision.

Group 2: Family members or friends of Group 1 (PLWHA) formed the second group. There were only 77 people in this group as some PLWHA did not nominate anyone to whom they disclosed their HIV status to participate.

Group 3: This group is consisting of 50 participants. Out of this number 31 are community members and 19 are opinion leaders. The 31 community members were recruited after community meetings (by the researcher) with the assistance of their community leaders such as village headmen. Those who were willing and eligible were selected through a simple random sampling process. Their names were put in a box and half of the names were selected randomly after each meeting. All the 19 interested opinion-leaders such as the constituency councillor, teachers, church leaders, peer educators and village headmen were included in the study.

Group 4: This group consisted of four health care workers from the only clinic that provides antiretroviral drugs (ARVs) in the study setting. All health care workers who worked at the clinic at the time of the study were recruited voluntarily.

\subsection{Study Instruments}

The study used three stigma measurement instruments (questionnaires) as well as an interview guide. The instruments were HIV/AIDS Stigma Instrument for people living with HIV/AIDS (HASI-P) developed by Holzemer et al. [13] for five African countries study: Lesotho, Malawi, South Africa, Swaziland, and Tanzania, that was modified by the researcher, the HIV/AIDS Stigma Instrument for Nurses (HASI-N) developed by Uys et al. [14], and Family and Community Stigma Instrument (F\&C-SI) developed by the researcher based on a Namibian survey and on material founded in the literature.

HASI-P included six factors with 33 items, but for this study one factor (health neglect) was omitted, as the study was conducted in communities other than in health facilities. The modified instrument therefore had five factors with 24-items and measured fear of contagion, verbal abuse, social isolation, workplace stigma and negative self-perception. This instrument was applied to Group1 (PLWHA). HASI-N was not modified and had two factors with 19-items which measures nurse stigmatizing patients and nurses being stigmatized by others. This instrument was applied to Group 4 (health care workers). Both instruments used Likert scales (never, once or twice, several times and most of the time) [13] [14] which were validated by their developers.

The F\&C-SI was developed by the researcher based on a Namibian baseline survey with additional questions from a survey on HIV/AIDS stigma developed by John Hopkins University Centre for Communication Programs in collaboration with the University of Namibia (UNAM) in 2002. Relevant items founded in the literature were added resulting in eight factors with 34-items used both continuous (strongly disagree to strongly agree) and categorical scales (yes or no) or Likert scale. The factors used to measure stigma were: community attitude, family attitude, personal attitude, household stigma, community opinion, close relationship, caring for a sick relative and fear of contagion. The F\&C-SI consisted of both negatively and positively worded items but, during analysis it was found that this complicated the survey and they were revised to be negatively worded to prevent response bias (see appendix). It is therefore recommended that for future use, this instrument be revised to make all the items negatively worded.

\subsection{Data Analysis}

The data was analyzed with Predictive Analytics Software (PASW) Statistic 18 program. Descriptive and ana- 
lytic statistics were used and qualitative data was content analyzed manually.

\section{Ethical Considerations}

Ethical approval was obtained from the Biomedical Ethics Committee from University of Kwa Zulu-Natal (UKZN), South Africa (approval number: HSS/0962/2009) and the Ministry of Health, Namibia (Ref: 17/3/3/ AP). Permission was obtained from the Ongenga Constituency Councillor where the study was conducted. Participants gave individual informed consent and were provided with information, which included voluntarily participation.

\section{Results and Discussions}

The study results are presented and discussed according to the three most common types of stigma which are external, internal and stigma of association as reported by the four groups of participants. Although the quantitative and qualitative data were analyzed separately, the results will be discussed together in this paper.

\subsection{External Stigma}

At baseline assessment, statistical analysis has shown that external stigma was high and included the following four factors: fear of becoming infected through casual contacts, verbal abuse, social isolation of persons who are HIV positive and discrimination at workplace based on their status. These findings are consistent with results from previous studies elsewhere in Africa [9] [15].

Fear of contagion: The stigma score due to fear of becoming infected through non-sexual casual contacts is low as majority of PLWHA 85\% $(n=79)$ reported that they never experienced it in the last three months at the time of assessment. Likewise family and community participants $(96 \%$ to $100 \%$; $n=127)$ confirmed that they do not have problem with day-to-day contacts with people who are living with HIV for example they would eat food prepared and share toilets with persons who are HIV positive or have AIDS. They have also indicated that they are willing to care for sick relatives who are HIV positive. Following the results one can possibly attribute that there is more understanding on HIV transmission and less fear that people cannot get infected by caring and interacting with PLWHA. The study participants were given a series of statements to indicate how often they experienced stigma as a result of fear of contagion and it was found that only $17 \%(n=16)$ of PLWHA reported that they were asked to leave due to coughing but this could be linked to TB rather than to fear of HIV contagion. People are aware that coughing is one of the signs of TB and this could be the reason for asking PLWHA to leave when they started to cough and does not necessary mean that they discriminate them due to fear of getting HIV.

However some participants who were interviewed revealed that there is stigma due to fear of contagion in the community which is evident from this statement: "some people are afraid to buy food cooked by people who are HIV positive. People fear of getting the disease. Even me, I am uncomfortable buying food from people who are HIV positive." Additionally, one participant indicated that fear of contagion is experienced at schools as it was expressed in this statement: "some learners do not want to play with infected learners or to share books with them." "They do not want to be in same group work with those learners."

Although participants in this study reported cases of stigma due to fear of contagion, it did not occur frequently. It can therefore be argued that there is less fear of becoming infected through non-sexual casual contacts and more understanding on how HIV is transmitted. Interventions in knowledge on basic facts of HIV transmission needs to be strengthened in order to reduce stigma among families and community members.

Verbal abuse: Verbal abuse has manifested in different ways as this study found that PLWHA experienced being called names, being blamed for immoral behaviours such as promiscuous, judged as well as insulted either by family or by community members. The results from the PLWHA group $(n=92)$ revealed that verbal abuse in the form of blaming, judging, insulting and name calling was experienced (mean: 1.19; standard deviation: 1.02) (Table 1). Similarly the results from interviews revealed that PLWHA are verbally abused by their families and relatives. They use bad phrases and words such as: "You have looked for it". The results further revealed that there are people who still believe that HIV is a punishment from God and this could be linked to the belief that those who have the virus are promiscuous and have immoral behaviours. These findings are similar to what has been reported from a qualitative study conducted by Nghifikwain 2011, in Namibia. Additionally these findings 
Table 1. Frequencies of verbal abuse experienced by PLWHA.

\begin{tabular}{ccccc}
\hline Items & $\begin{array}{c}\text { No. of participants } \\
\text { responded }\end{array}$ & Never & Once or twice & $\begin{array}{c}\text { Several times \& } \\
\text { most of the time }\end{array}$ \\
\hline I was called bad names. & 91 & $38 \%$ & $5 \%$ & $55 \%$ \\
People sang offensive songs when I passed by. & 91 & $56 \%$ & $1 \%$ & $41 \%$ \\
I was told that I have no future. & 89 & $57 \%$ & $4 \%$ & $40 \%$ \\
Someone scolded me. & 89 & $42 \%$ & $11 \%$ & $43 \%$ \\
I was told that God is punishing me. & 90 & $63 \%$ & $2 \%$ & $33 \%$ \\
Someone insulted me. & 89 & $52 \%$ & $11 \%$ & $40 \%$ \\
\hline
\end{tabular}

confirm what has been reported by Greeff and colleagues as respondents in their study reported that they were called prostitutes and people sing funeral songs when they talk about them [16]. In this study verbal abuse was also reported in the health facilities where care providers are expected to sympathize with PLWHA. Participants reported that health care providers directed bad phrases and words to persons who are HIV positive or have AIDS such as that: "You are finishing medications"; "What is the use to take vitamins?"; "Do you know that you are waiting for AIDS?” Furthermore some PLWHA reported that health care providers denying them essential services due to their HIV status. Although health care workers denied stigma in health facilities, PLWHA indicated that they were stigmatized by health care providers such as being denied vitamins. These findings are supporting studies from elsewhere in Africa [17].

According to the qualitative findings verbal abuse was not only directed to adults who are living with HIV, but was also experienced by children who are orphans due to HIV/AIDS, particularly those on ARVs. This is evident from this statement: "we are not the cause of your mother's death". Although stigma on children was not the focus of this study it is equally important to explore more on how they experience it, particular those who are orphans or having HIV positive caregivers. Verbal abuse findings from this study are similar with results from researches elsewhere, where it was reported in the form of words, offensive songs and phrases directed to PLWHA either by relatives, health care providers or community members [17] [18].

Social isolation: Social isolation can be as a result of either people who avoid persons who are HIV positive or from PLWHA who withdraw themselves from their family and community due to fear of rejection [16]. In this study social isolation score $(\mathrm{n}=93$; mean: 1.02; standard deviation 0.96$)$ was the second highest form of stigma. PLWHA $(34 \%, \mathrm{n}=30)$ reported that people avoided them, $(36 \%, \mathrm{n}=33)$ participants reported that people stopped their friendships and ended relationships after they learnt that they are HIV positive (Table 2). It was found that people do not want to chat with PLWHA $(30 \%, n=28)$ and do not visit them $(37 \%, n=34)$ anymore as they used before knowing their status.

According to this study's findings sometimes neighbors visit to see the condition of the sick person so that they can go and gossip, after which they stop visiting. This was reported by one participant who said: "Gossiping about people who are HIV positive is very high in our community. People are afraid to disclose their HIV status because of stigma."

The study findings revealed that there are reports of children not allowed to play with a neighbour's children who are suspected of having HIV/AIDS. This study further found out that PLWHA are being isolated socially by family, friends and community members. This reflects either on fear of being associated with someone who is HIV positive or it could be linked to shame related to the most common mode of its transmission. Similarly Greeff et al. reported the same form of stigma where children were told not to go to the homestead of a person who is HIV positive [16].

Interviews with opinion leaders revealed that there are reports of persons being isolated socially by colleagues at workplace due to their HIV positive status. This form of stigma can cause stress and depression in PLWHA, therefore people need to be educated and informed on stigma reduction strategies. This study found out that some PLWHA isolated and regarded themselves as sick people and they withdrew from society. They isolate themselves to avoid rejection or disclosing their HIV status. In some cases they do it to protect their beloved ones from stigma of association as social isolation may correspond to low level of disclosure to family and 
Table 2. Frequencies of experienced stigma in the form of social isolation.

\begin{tabular}{|c|c|c|c|c|}
\hline Items & $\begin{array}{l}\text { No. of participants } \\
\text { responded }\end{array}$ & Never & $\begin{array}{c}\text { Once or } \\
\text { twice }\end{array}$ & $\begin{array}{l}\text { Several times and mos } \\
\text { of the time }\end{array}$ \\
\hline Someone stopped being my friend. & 92 & $58 \%$ & $5 \%$ & $36 \%$ \\
\hline A friend would not chat with me. & 84 & $58 \%$ & $2 \%$ & $30 \%$ \\
\hline People avoided me. & 89 & $53 \%$ & $9 \%$ & $34 \%$ \\
\hline People cut down visiting me. & 89 & $58 \%$ & $1 \%$ & $37 \%$ \\
\hline People ended their relationship with me. & 91 & $57 \%$ & $5 \%$ & $36 \%$ \\
\hline
\end{tabular}

friends. Research elsewhere has confirmed that social isolation and withdrawal are barriers to HIV response as they prevent PLWHA to seek for health care, despite needing access to medical services. PLWHA and their caregivers should be educated on the disadvantages of self-isolation, social withdrawal and its effects on their well-being. Counselling services need to be tailored to reach them, their families as well as community at large. It is high time for HIV/AIDS to be seen and regarded as any other chronic disease so that infected and affected people can enjoy equal rights in a culture of acceptance, openness as well as compassion. HIV/AIDS should become a "spoken" disease and not a "whispered" one.

Household stigma: Household stigma was also reported which could be linked to lack of knowledge, myths and misconception on HIV transmission. With correct information and re-education on how HIV is transmitted, people are likely to change their behaviour and attitudes towards those who are living with the disease. PLWHA revealed that they were asked to leave when they coughed which could be linked to fear of TB or lack of knowledge about HIV transmission. Similarly, reports from families and community leaders who were not willing to care for someone who was in an accident can be linked to fear of contaminated blood and not necessarily stigma.

Family and community attitude towards PLWHA: Family members and community leaders reported low stigma towards PLWHA as they confirmed that they would be taking care of their sick relatives and did not isolate them, but this was not supported by results from the interviews. There were reports of people being verbally abused in their households, bad phrases were used towards orphans who are HIV positive, and they were denied food that they needed before taking their ARVs. There were reports of avoidance and people being hidden from visitors due to fear of stigma of association. It is therefore anticipated that the participants gave social acceptable answers rather than telling the truth.

\subsection{Internal Stigma}

Internal, felt, imagined or self-stigma is the shame and fear associated with HIV/AIDS as a result it impacts on people's daily life, it affects the way in which they cope with their HIV positive status and how they behave [19].

Negative self-perception: Results of this study revealed that internal stigma is experienced by people who are HIV positive. The negative self-perception mean score is 0.68 and a standard deviation of 0.9 ( $\mathrm{n}=93$ ). Out of 93 PLWHA participants $19 \%(n=17)$ reported felt that they did not deserve to live, $21 \%(n=20)$ were ashamed of having the disease, $25 \%(n=23)$ felt worthless and $21 \%(n=20)$ said they no longer felt like persons. The $33 \%(n=31)$ of PLWHA confirmed that they felt brought trouble to their families (Table 3). These kinds of feelings could result in negative actions such as stress, depression and decision to commit suicide. Evidently one participant revealed that: "Some PLWHA abuse alcohol because they do not want others to know that they are HIV positive. Yes stigma does exist.” This could be related as an example of a negative action due to self-stigma. The feeling of bringing trouble to the family can be associated with blame and judgment from families and relatives. Feeling guilty and a burden to their loved ones do not necessary mean that families have the same feelings against them.

Although it is less than half of participants who reported self-stigma, it is still a concern as it is the chief obstacle in HIV response in Namibia. Studies elsewhere have shown that self-stigma blocks HIV response, for example in India an HIV positive mother was afraid to stop breastfeeding her baby due to fear of her family to suspect her HIV status. A man in Botswana decided not to take ARV as he associated HIV with death. A sex 
Table 3. Frequencies of negative self-perception among PLWHA.

\begin{tabular}{|c|c|c|c|c|}
\hline Items & $\begin{array}{c}\text { No. of } \\
\text { participants } \\
\text { responded }\end{array}$ & Never & $\begin{array}{c}\text { Once } \\
\text { or twice }\end{array}$ & $\begin{array}{l}\text { Several times and most of } \\
\text { the time }\end{array}$ \\
\hline I felt that I did not deserve to live. & 91 & $77 \%$ & $1 \%$ & $19 \%$ \\
\hline I felt ashamed of having this disease. & 89 & $71 \%$ & $4 \%$ & $21 \%$ \\
\hline I felt completely worthless. & 91 & $70 \%$ & $3 \%$ & $25 \%$ \\
\hline I felt that I brought a lot trouble to my family. & 90 & $56 \%$ & $8 \%$ & $33 \%$ \\
\hline I felt that I am no longer a person. & 90 & $75 \%$ & $1 \%$ & $21 \%$ \\
\hline
\end{tabular}

worker in Cambodia does not visit clinic regularly for STI treatment due to fear of blame and judgment from health care workers [19]. Self-stigma was also reported in a Ugandan study (2011) where it remains powerful as participants describing themselves as "useless" and "same as dead" [15].

Participants in this study suggested that continuous counselling is needed for PLWHA as they are stressed and sometimes for no reason. Similarly the authors for Ugandan study suggested that future interventions should be aimed at empowering PLWHA that will help to improve their quality of life [15]. Equally, this study supports these suggestions.

\subsection{Stigma of Association}

According to Holzemer and Uys (2004) health care workers are the recipients of stigma as they provide care to PLWHA but they are also regarded as the source of stigma by persons who are HIV positive [20].

Nurse stigmatized by community: Although health care workers indicated no stigma in health facilities, they confirmed that nurses are being stigmatized by community as the community suspects that those who care for HIV/AIDS patients also have the virus. The spouses of nurses fear that they will get the virus from work and infect them. This study did not explore stigma of association against caregivers with other participants rather than the four health care workers from the ARV clinic. It was one of this study's limitations however future researchers can take this further.

\section{Limitations}

This study was limited to a rural community and only PLWHA who were members of Opawa Support Group have participated. Some prominent community leaders were reluctant to participate in the study. Due to limited resources, the researcher could not give incentives to study participants as a norm in HIV/AIDS related studies. These limitations have influence on the generalization of this study's findings.

\section{Conclusions}

This study's findings are consistent with other studies done in Africa and Namibia, in particular indicating that people living with HIV/AIDS experience stigma in their families as well as in the community with verbal abuse, social isolation and negative self-perception being most common [9] [17]. These forms of stigma are trigged by other factors such as lack of knowledge and understanding of how HIV is transmitted, therefore fear of being associated with HIV positive persons and fear of getting the virus through non-sexual casual contacts. The absence of continuous counselling services in the community and the frustration of caring sick relatives with limited or no resources also causes stigma.

This study has concluded that stigma related to HIV and AIDS manifests in different ways in Namibia and interventions are needed to address and reduce it. A community-based HIV/AIDS stigma reduction intervention was developed for a rural community by the author and it will be discussed in a different paper. Although the new instrument has shortcomings the results for this study serves as baseline for future studies in Namibia.

Additionally the newly developed family and community stigma instrument was useful and reliable but that some of the limitations need to be changed for future use. Firstly, the wording of the items should be in the same direction (negatively worded) to prevent confusion and bias during data analysis. Secondly, items on close relative PLWHA (section three of questionnaire) should be removed, its Corrected Item Total Correlation was 0.250, 
indicating that they do not measure stigma. Thirdly, fear of contagion items showed a negative value $(-0.069)$ in Inter Item Correlation Matrix, indicating that it measures something different from the scale; therefore it should be removed or revised and tested before final use. Additional items can be added to improve the instrument and increase its reliability.

This study recommends that further studies are needed to explore stigma among children in a Namibian context. There is also a need to explore the link between stigma and poverty as it is believed that they are twinned. More counseling services are needed in the community to help PLWHA to overcome self-stigma. Families and caregivers of PLWHA also need counseling and psychological support that would empower them and contribute to stigma reduction in family. Community meetings were identified as effective strategy to give information to community members, it is therefore recommended and it needs to be applied in stigma reduction. Local community-based, faith-based organizations and other related groups in the community need to collaborate in stigma reduction activities. Lastly HIV/AIDS should become a “spoken” disease and not a “whispered” one.

\section{Acknowledgements}

The corresponding author would like to acknowledge Fogarty AIDS International Training and Research Program (AITRP) for granting her scholarship for three years to pursue her study, from which this paper has been emerged. The author acknowledges all the institutions and organizations (UNAM, UKZN, CAPRISA, Namibia Ministry of Health, Opawa Support Group, Ongenga Constituency Councillor) which contributed to this study in one way or another. The corresponding author further acknowledges the statistician Ms F. Nkwanyana who assisted with data analysis, Ms C. Martin who edited the thesis, and all study participants without their participation this study could not be materialized.

\section{References}

[1] Ministry of Health and Social Services (2010) Report of the 2010 National HIV Sentinel Survey. Author, Windhoek.

[2] University of Namibia (2008) HIV and AIDS Resource Guide. Faculty of Medical and Health Sciences. University of Namibia, Windhoek.

[3] Ministry of Health and Social Services (2006) Plan for National Multisectoral Monitoring and Evaluation of HIV/ AIDS. Author, Windhoek.

[4] Goffman, E. (1963) Stigma: Notes on the Management of Spoiled Identity. Prentice-Hall, Englewood Cliffs.

[5] Brown, L., Trujillo, L. and Macintyre, K. (2003) Interventions to Reduce HIV/AIDS Stigma: What Have We Learned? AIDS Education and Prevention, 15, 49-69. http://dx.doi.org/10.1521/aeap.15.1.49.23844

[6] Angula, P. (2008) The Accessibility of HIV/AIDS Related Health Information to People Living with HIV/AIDS in Khomas Region, Windhoek. Unpublished Master's Thesis, University of Namibia, Windhoek.

[7] Keulder, C. (2007) HIV/AIDS and Stigma in Namibia: Results of a Qualitative Study among Support Group Members. Author, Windhoek.

[8] Mufune, P. (2003) Changing Patterns of Sexuality in Northern Namibia: Implications for the Transmission of HIV/ AIDS. Culture, Health and Sexuality, 5, 425-438. http://dx.doi.org/10.1080/136910501165631

[9] Nghifikwa, L. (2011) The Perception and Experience of Stigma and Discrimination among HIV-Positive People at Oshakati ARV Clinic in Oshana Region, Namibia. Master’s Thesis. http://hdl.handle.net/1009.1/6785

[10] Thomas, F. (2007) “Our Families Are Killing Us”: HIV/AIDS, Witchcraft and Social Tensions in the Caprivi Region, Namibia. Anthropology \& Medicine, 14, 279-291. http://dx.doi.org/10.1080/13648470701612679

[11] Naidoo, J.R., Uys, L.R., Greeff, M., Holzemer, W.L., Makoae, L.N., Dlamini, P.S., Phetlhu, R.D., Chirwa, M. and Kohi, T. (2007) Urban and Rural Differences in HIV/AIDS Stigma in Five African Countries. African Journal of AIDS Research, 6, 17-23. http://dx.doi.org/10.2989/16085900709490395

[12] Cresswell, J.W. (2009) Research Design. Qualitative, Quantitative, and Mixed Methods Approaches. 3rd Edition, SAGE Publications Inc., Singapore.

[13] Holzemer, W.L., Uys, L.R., Chirwa, M.L., Greeff, M., Makoae, L.N., Kohi, T.W., Dlamini, P.S., Stewart, A.L., Mullan, J., Phetlhu, R.D., Wantland, D. and Durrheim, K. (2007) Validation of the HIV/AIDS Stigma Instrument-PLWA (HASI-P). AIDS Care, 19, 1002-1012. http://dx.doi.org/10.1080/09540120701245999

[14] Uys, L., Holzemer, W.L., Chirwa, M., Dlamini, P., Greeff, M., Kohi, T.W., Makoae, L.N., Stewart, A.L., Mullan, J., Phetlhu, R.D., Wantland, D.J., Durrheim, K.L., Cuca, Y.P. and Naidoo, J.R. (2009) The Development and Validation of the HIV/AIDS Stigma Instrument-Nurse (HASI-N). AIDS Care, 21, 150-159. 
http://dx.doi.org/10.1080/09540120801982889

[15] Nattabi, B., Li, J., Thompson, S.C., Orach, C.G. and Earnest, J. (2011) Factors Associated with Perceived Stigma among People Living with HIV/AIDS in Post-Conflict Northern Uganda. AIDS Education and Prevention, 23, $193-205$. http://dx.doi.org/10.1521/aeap.2011.23.3.193

[16] Greeff, M., Uys, L.R., Holzemer, W.L., Makoae, L.N., Dlamini, P.S., Kohi, T.W., Chirwa, M.L., Naidoo, J.R. and Phetlhu, R.D. (2008) Experiences of HIV/AIDS Stigma of Persons Living with HIV/AIDS and Nurses Involved in Their Care from Five African Countries. Africa Journal of Nursing and Midwifery, 10, 78-108.

[17] Dlamini, P.S., Kohi, T.W., Uys, L.R., Phetlhu, R.D., Chirwa, M.L., Naidoo, J.R., Holzemer, W.L., Greeff, M. and Makoae, L.N. (2007) Populations at Risk across the Lifespan: Empirical Studies Verbal and Physical Abuse and Neglect as Manifestations of HIV/AIDS Stigma in Five African Countries. Public Health Nursing, 24, 389-399. http://dx.doi.org/10.1111/j.1525-1446.2007.00649.x

[18] Rutledge, S.E., Abell, N., Padmore, J. and Mccann, T.J. (2008) AIDS Stigma in Health Services in the Eastern Caribbean. Sociology of Health \& Illness, 31, 17-34. http://dx.doi.org/10.1111/j.1467-9566.2008.01133.X

[19] Brouard, P. and Wills, C. (2006) A Closer Look: The Internalization of Stigma Related to HIV. US Agency for International Development, Washington DC.

[20] Holzemer, W.L. and Uys, L. (2004) Managing AIDS Stigma. Journal of Social Aspects of HIV/AIDS, 1, 165-174. http://dx.doi.org/10.1080/17290376.2004.9724839 